\title{
GIS-BASED OPTIMUM SITE SELECTION FOR SOLAR ELECTRIC VEHICLE CHARGING STATION: ANKARA-ISTANBUL HIGHWAY CASE
}

\author{
S. Hisoglu ${ }^{1}$, R. Comert ${ }^{2}$ \\ ${ }^{1}$ Gumushane University, Department of Civil Engineering and Geomatics Engineering, Gumushane, Turkey - sinemhisoglu61@ gmail.com \\ ${ }^{2}$ Gumushane University, Department of Geomatics Engıneerıng, Gumushane, Turkey - rcomert@gumushane.edu.tr
}

Commission IV, WG IV-I

KEY WORDS: Renewable Energy, Solar Energy, Sustainability, GIS, Electric Vehicle Charging Station, Solar Site Selection.

\begin{abstract}
:
Energy sources are divided into renewable and non-renewable sources. It can be seen that non-renewable energy resources are not adequately meeting the increased demands of worldwide technological developments, increasing population, and global consumption. Therefore, the demand for renewable resources is increasing day by day. When it comes to the use of non-renewable carbon-based fossil fuels, one of the first areas that come to mind is undoubtedly the Automotive sector. Today, it is realized that one of the main reasons for the lack of electric motor cars compared to petroleum fuelled cars, is the scarcity of electric vehicle charging stations and the difficulty of their accessibility. In this study; an analysis of solar-powered electric charging stations site selection was carried out for electric vehicles. The Ankara-Istanbul highway, which has a high traffic density, was chosen as the sample route for the study. Within the scope of the study, the areas where stations can be installed on the highway were carried out using the MultiCriteria Decision Making Method with the help of Geographic Information System. Solar radiation, slope, aspect, land use/land cover, traffic volume and proximity to the road, criteria of the route, and site selection analysis were determined as input data. The maps of the determined criteria were arranged according to the study area and prepared for analysis. The criteria maps obtained were reclassified according to the above-mentioned criteria and scoring system. After the reclassification process, the weighting of each criteria which affect the analysis was determined by the researched literature and an overlapping process was carried out. According to the results map produced as a result of the overlay analysis, the appropriate area has been determined for the electric charging stations working with solar energy. On the defined route within the scope of the study, a proposal has been made for a total of 13 stations, 8 in Ankara, 3 in Bolu, 1 in Kocaeli, and 1 in Istanbul. This study, it is aimed to encourage automobile users to make greater use of electric motor vehicles, which would be a more environmentally friendly and sustainable choice, and ultimately more economical.
\end{abstract}

\section{INTRODUCTION}

Today, in parallel with population growth, technological development, and the diversification of our needs, the energy demand is increasing daily. Due to the negative effects of nonrenewable energy sources, the demand for renewable energy consumption is increasing in almost every field of human activity. (Çanka Kılıç, 2015).

When it comes to the use of non-renewable energy, one of the common areas of use is undoubtedly the transportation sector. Looking at the European Commission data, it is seen that most of the environmental and economic energy needs in the transportation sector are currently based on oil. The electric vehicle industry is now regarded as the best alternative to reduce the dependency on oil in the transportation sector and to develop a more environmentally friendly policy (European Commission, 2019).

Founded in 2018, Turkey's Automobile Enterprise Group Industry and Trade Inc. predict that the development in the electric vehicle market will accelerate with the national development movement initiated in the electric vehicle market
(Sağlam et al., 2021). In this context, the importance of increasing the number of electric vehicle charging stations has been determined to contribute to the development of the electric vehicle industry in our country and to become a pioneer in its expansion (Turkish National Committee, 2017).

Hydraulic, wind, geothermal, biomass, and solar sources can also be used to produce renewable electricity (Ministry of Environment and Urbanization, 2018). When renewable resources for electricity generation are compared, the solar potential of Turkey is high due to its geographical location (Y1lmaz, 2012). Therefore, it is reasonable to predict that, the electric energy required for electric vehicle charging stations, in areas with high solar energy potential on highways and provincial roads used in our country, can be produced from the sun.

Undoubtedly, the most important parameter for the installation of solar charging stations in suitable places on the determined routes is the solar energy potential of the region. However, taking into account the environmental, socio-economic, and terrain conditions of the stations to be established will enable the selection of the most suitable places to be made. In this context, it is seen that choosing a suitable location for solar 
electric charging stations is a spatial problem that requires the consideration of multiple criteria. The Multi-Criteria Decision Making (MCDM) process is a decision-making approach that allows choosing the most suitable area among the alternative areas by considering multiple criteria (Sánchez-Lozano et al., 2016). Since location analysis is a spatial problem, Geographical Information Systems (GIS), which allows the analysis of spatial data, is a technology that can be used effectively in MCDM analysis (Deniz and Topuz 2018).

In this study, a suitable site selection analysis was made for the charging stations required by electric vehicles using solar energy on the Ankara-Istanbul route. Station location suggestions were made for the places where solar charging stations can be installed in those areas identified as a result of the process. Site selection analysis was carried out in ArcGIS software, a GIS software.

The main purpose of the study is to select suitable locations for solar energy-based electric charging stations for electric vehicles, which is one of the most reliable sustainable energy sources. In this way, it is aimed to contribute to the creation of a more environmentally friendly and sustainable world by encouraging the use of electric vehicles using renewable energy. The study aims to identify the ideal locations for the installations that can address the problem of vehicle charging stations and accordingly contribute to the increase in the number of electric vehicle users. The lack of charging stations is one of the reasons why drivers currently do not choose electric vehicles and prefer to continue with internal combustion vehicles.

Today, the use of motorized vehicles is increasing day by day and the vast majority of vehicles in operation use fossil fuels. Similarly, the majority of electric energy generation in the world uses fossil fuels. This situation causes environmental pollution to the greatest extent, and therefore a sustainable environment needs to reduce the use of fossil fuels in electricity generation to meet the energy needs of environmentally-friendly electric vehicles, by creating an infrastructure of environmentally-friendly electric charging stations. To this end, choosing suitable locations for solar-powered electric charging stations in the study is important in terms of increasing availability and access to solar-generated energy to contribute to a cleaner environment.

There are suitable site selection studies for electric vehicle charging stations in the literature (Chen, 2017; Kaya, 2020). In addition, there are solar field site selection studies for solar power generation (Yalçın, 2020; Gerçek, 2018; Ayday, 2016). When the electric vehicle charging station location selection, which is the common point of these two issues, is examined, it is seen that there has not been a location selection study for charging station installations based on renewable energy. In this context, the analysis of electric charging stations operating with solar energy is the first in the field of site selection analysis.

\section{STUDY AREA}

An important factor when determining the application area, and considering the intercity travel of drivers, was the necessity of recharging the electric vehicle ranges over long distances, and determining the requisite installation of the charging stations on the highway route gained importance. For this reason, the Ankara-Istanbul highway, which connects Ankara and Istanbul (Gönül et al., 2021), the two cities with the highest electric vehicle usage rates in Turkey, was chosen as the selected route to determine the electric charging station location requirements. As a study area, the Ankara-Istanbul highway is 443 kilometers in total. From Ankara to Istanbul, respectively; Bolu, Düzce, Sakarya, Kocaeli are the cities within the route (Figure 1.).

When the renewable energy potentials and the practicality of use are compared within the determined route, it is seen that the power to be obtained by using solar energy will give more adequate results (URL1). Therefore, solar energy was chosen as the primary renewable energy source for the study.

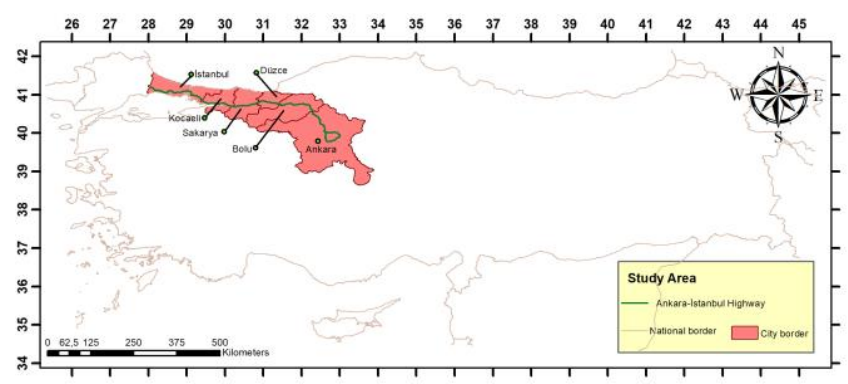

Figure 1. Study area

\section{METHODOLOGY}

The workflow implemented within the scope of the study is given in Figure 2. Within the scope of the study, first of all, the criteria to be used in the site selection analysis were determined. After the criterion determination process, the criteria maps were prepared according to the study area and made ready for analysis. The criteria maps obtained were reclassified according to a determined scoring system. As a result of the classification process, the weights of each criterion that will affect the analysis were determined by literature research, and the overlapping process was carried out. At the last stage of the study, station locations where electric charging stations can be established were determined according to the resulting map produced as a result of the overlap analysis.

\subsection{Criteria Affecting Study Site Selection}

To determine the solar-powered electric vehicle charging station installation areas on the Ankara-Istanbul Highway route, assistance was obtained from postgraduate theses, periodicals, corporate reports or publications in the literature, and online publications. (Lindberg, 2021; Bayram, 2021; İbrahim, 2020; Soydan, 2020) ; Gerçek, 2018; Uyan, 2013). As a result of the examinations, three main headings were discussed in terms of economic, environmental, and social aspects. Economically; solar potential, slope, aspect and traffic volume, environmental 
aspects; land use/land cover (LU/LC), and the criterion of proximity to the road in terms of social aspects were discussed.



Figure 2. Applied methodology in the study

Solar radiation: The most important criterion for the suitability analysis of the selected route within the study is the determination of the solar energy potential. The area to be selected for the station installation must have a high solar radiation value. Installing a solar-based station in areas with low solar radiation value is not a desirable situation considering efficiency and cost. Solar radiation tools in ArcGIS, the GIS software, were used to generate solar radiation belonging to the study area.

Slope: The slope criterion is important in terms of the cost of the station to be installed. Solar panels are usually installed in areas with shallow slopes to reduce the cost of the study. The slope of the land is a very important parameter for the photovoltaic panels to be used in solar energy production to be installed within the scope of the study.

Aspect: Turkey is geographically located in the northern hemisphere. Therefore, the sun's rays falling on our country come from the south. To obtain high-efficiency energy in solar panel installation, it is of great importance that the selected areas are south-facing. For this reason, the aspect criterion has an important place in the analysis process.

Traffic volume: The study route is the Ankara-Istanbul Highway, one of the highways with the heaviest traffic volume in Turkey. Since it is known that the number of electric vehicles will be higher in direct proportion to the vehicle density, the vehicle density has an important place for the location selection in the charging station installation.

Land use/Land cover (LU/LC): One of the important criteria that should be known for the study site selection is the CORINE; (Coordination of Information on the Environment, URL2). It will not be appropriate to establish the station on land use areas such as forests and fertile agricultural lands. Therefore, land use/land cover is also an important criterion in site selection analyses.

Distance from highway: When vehicle fuel purchases are considered, the proximity to the road criterion is one of the more important criteria in station location selection, since it is thought that the preference of the station to be selected on or near the route will increase the preferability.

\subsection{Criteria Rank}

Each of the criteria used within the scope of the study are mapped in a separate unit. For example, slope data is in percent, aspect data is in angle, solar data is in kWatt. To perform an overlay analysis with these data, each criterion must be reclassified according to the common scoring system. The criteria used within the scope of the study were reclassified by scoring from 1 to 5 according to their suitability for the installation of electric charging stations. 5 represents the highest available area and 1 represents the lowest available area. Areas with a score of 0 within the scope of the study represent areas that are unsuitable for analysis of station installation.

\subsection{Analysis and Determination of Stations}

In multi-criteria decision-making processes, appropriate site selection processes are carried out by considering multiple criteria. Within the scope of this study, the weighted overlay process was applied in the site selection process. The weighted overlay process is a method that produces results in the same value ranges as the scoring values, by overlaying according to the effect ratios of the criteria in a common scoring system on the overlay. The layer weights used in the study were obtained as a result of literature reviews. While determining these weights, articles in which solar farm location selection was made with GIS were used (Tercan, 2021; Prieto-Amparán, 2021; Zambrano-Asanza, 2021; Ali et al., 2019).

While determining the proposed stations, it has been calculated how many charging units will be in the station to be installed, how many panels will be installed in the area, how much energy these panels will produce, and how much area they will need. According to the station area obtained as a result of the calculation made, the suggested station locations were determined on the result map.

\section{RESULTS}

Using six different criteria, a suitable site selection analysis was carried out for suitable solar-powered charging stations that can be built on the Ankara-Istanbul highway route. For the six criteria determined in the study, firstly, the reclassification process was carried out according to the determined point values. The values assigned for the criteria used according to this scoring system are shown in Table 1.

After the scoring stage of the criteria, the weights of each criterion were determined in the production of the suitability map, depending on the literature research. Among the criteria used in this context, solar radiation is weighted as $30 \%$, traffic volume $20 \%$, slope $15 \%$, land use/land cover $15 \%$, aspect $10 \%$, and proximity to the road $10 \%$. Overlay analysis was performed according to the determined weight values. The resulting map is shown in Figure 3. While assigning the suitability values, the results obtained from the map were defined as the most suitable 
areas between 4-5 rank, suitable areas between 3-4 rank, less suitable areas between 2-3, and unsuitable areas between $0-2$. When Figure 3. is examined, it is seen that the most suitable areas are gathered around the province of Ankara. The main reason for this is that the highest weight value is given to solar radiation in the overlay analysis and solar radiation is higher in and around Ankara than in other provinces.

\begin{tabular}{|c|c|c|c|}
\hline Land use/Land cover (CORINE 2018 & & & Rank \\
\hline 2.3.1,2.4.3,3.3.1,3.3.2,3.3.3 & & & 5 \\
\hline 3.2.1,3.2.3,3.2.4 & & & 4 \\
\hline 1.4.1,2.1.1,2.1.2 & & & 3 \\
\hline 1.1.2,1.2.1,2.4.2 & & & 2 \\
\hline 1.1.1,1.2.2,1.4.2 & & & 1 \\
\hline 1.2.3,1.2.4,1.3.1,1.3.2,1.3.3,2.2.3,3 & 3,4.1.1, & & 0 \\
\hline Solar radiation $\left(\mathrm{kWh} /\left(\mathrm{m}^{2}\right)\right)$ & Rank & Slope (\%) & Rank \\
\hline $1400<$ & 5 & $<6$ & 5 \\
\hline $1400-1300$ & 4 & $6-12$ & 4 \\
\hline $1300-1200$ & 3 & $12-18$ & 3 \\
\hline $1200-1100$ & 2 & $28-24$ & 2 \\
\hline$<1100$ & 1 & $24-30$ & 1 \\
\hline & & $30<$ & 0 \\
\hline Distance from highway (m) & Rank & Aspect (direction) & Rank \\
\hline $0-200$ & 5 & south & 5 \\
\hline $200-400$ & 4 & southwest - southeast & 4 \\
\hline $400-600$ & 3 & east-west & 3 \\
\hline $600-800$ & 2 & northwest-northeast & 2 \\
\hline $800-1000$ & 1 & north & 1 \\
\hline Traffic volume (total vehicles/day) & Rank & & \\
\hline $40000<$ & 5 & & \\
\hline $25000-40000$ & 4 & & \\
\hline $15000-25000$ & 3 & & \\
\hline $10000-15000$ & 2 & & \\
\hline$<10000$ & 1 & & \\
\hline
\end{tabular}

Table 1. Ankara-Istanbul Highway, layers included in weighted overlay analysis in electric vehicle charging station location selection

When the result map obtained as a result of the weighted overlay analysis is examined, the existence of suitable areas for the installation of the electric charging station photovoltaic panels on the selected route stands out. However, whether the most suitable areas obtained are suitable for station installation should be evaluated spatially. In this context, based on some assumptions, the minimum area for a station to be established has been calculated.

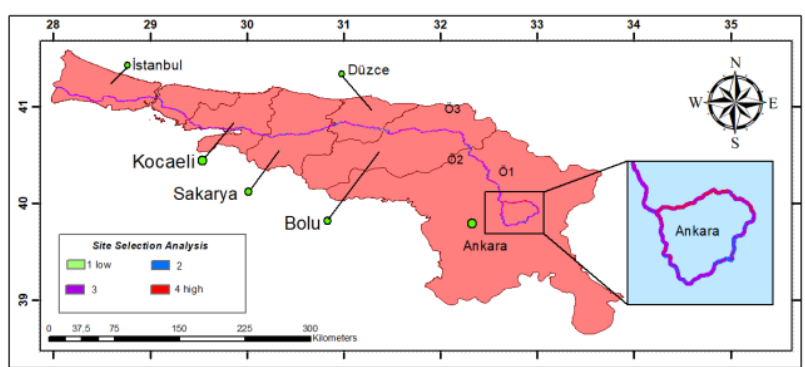

Figure 3. As a result of the weighted overlay analysis, the suitability map produced for the installation of a solar-powered electric charging station on the Ankara-Istanbul highway

The average values suitable for the selected criteria were accepted as follows;

- Energy production of the selected photovoltaic panel: $1 \mathrm{~kW} / \mathrm{h}$

- The approximate area of one panel is $1.9 \mathrm{~m}^{2}$

- Selected electric vehicle brand/model TOGG
- The engine power of the selected vehicle is $150 \mathrm{~kW}$

- Socket type determined for the station DC $50 \mathrm{~kW}$

- Average sunshine duration 6 hours

- Energy loss about $10 \%$

- The number of charging units considered in a station is 10

- The working capacity of the station is 24 hours

According to the calculation made as a result of the stated acceptances; one panel produces $2190 \mathrm{~kW}$ of energy per year. The daily energy amount needed by a station operating 24 hours a day is $12000 \mathrm{~kW}$, and the annual energy amount is 4380000 kW. 2000 panels are required for a station to operate with a capacity for 24 hours. After the calculated number of panels, it has been calculated that the required panel installation area should be 0.4 hectares for a station to operate at full capacity for 24 hours.

Based on the suitability map produced as a result of the calculations, the most suitable areas with 0.4 hectares were determined. The determined station points are 13 station locations that were proposed on the Ankara-Istanbul highway route (Figure 4). When the determined electric charging station locations are examined, a total of 13 stations have been proposed, 8 in Ankara, 3 in Bolu, 1 in Kocaeli, and 1 in Istanbul. Considering the above calculations, a total of 70 vehicles can be charged all day long from vehicles with a 150 KW engine from a station with 10 charging units.

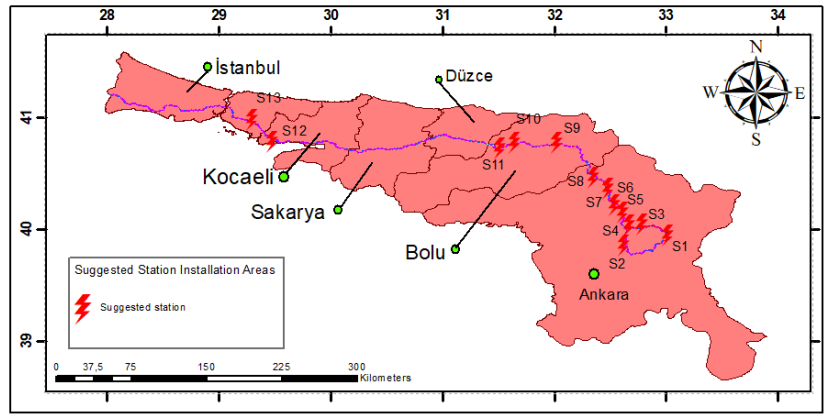

Figure 4. Suggested station installation locations based on the selected area map

\section{DISCUSSION}

In this study, a suitable solar-powered charging station location analysis was carried out for electric vehicles for the AnkaraIstanbul highway route. In the analysis process, solar radiation, traffic volume, slope, aspect, proximity to the road, and land use/land cover criteria were used. As a result of the analysis, a suitability map was produced for the relevant route. Appropriate station locations were suggested according to the station area determined on the appropriate map produced. A total of thirteen station locations were determined based on the minimum area needs. . When the results obtained are examined, the results in the regions of the route, especially in the borders of Ankara province, are satisfactory. 
In the study, solar radiation data was produced with the Area Solar Radiation tool of ArcGIS software over EU-DEM data with a spatial resolution of $25 \mathrm{~m}$. When the produced solar radiation data is examined, it is seen that the amount of radiation obtained has lower values when compared to the map produced by the HELIOSAT model of the General Directorate of Meteorology (URL3). When the studies in the literature are examined, it is seen that the solar radiation produced by the Area Solar Radiation tool produces lower values than the current values (Kausika et al., 2021). To obtain more accurate results from the produced solar radiation, this data should be calibrated with terrestrial measurements. In this way, more suitable places will be found in the provinces of Istanbul, Sakarya, and Kocaeli, where the route passes. In the future, the calibration of the produced solar radiation will be done and analysis results will be updated.

Six criteria were used for site selection analysis within the scope of the study. However, the number of these criteria can be increased considering the needs. For example, electric vehicles have a long charging time. Therefore, the fact that the stations to be established are close to the interaction centers can be added as a criterion to the study.

The calculations required to determine the minimum area of suitable station locations in the study were made according to DC $50 \mathrm{~kW}$ charging units, as they are used extensively in the market. Using these units prolongs the charging time. Recently, charging units capable of charging DC $180 \mathrm{~kW}$ per hour have been introduced to the market. Preferring these units at the stations to be installed will reduce the charging time of a vehicle with $150 \mathrm{~kW}$ engine power to 56 minutes. In this case, 250 vehicles can be charged per day at a station with ten units. However, in this case, the electricity need of the station will increase and the station installation area will increase to approximately 0.4 hectares. In future studies, site selection will be made according to solar radiation calibration and appropriate site determination will be made according to DC $180 \mathrm{~kW}$ units.

It is estimated that there will be an increase in the production of more efficient and less expensive photovoltaic energy panels with the developing technology in the future. In this way, the amount of energy production in the area to be selected will also increase, and charging stations can be established in smaller areas. In addition, the changes in the engine power and range capacities of electric vehicles are also expected to increase, and as a result of the calculations made within the future new data, will influence the station vehicle capacity or the amount of energy that a station needs to produce.

\section{CONCLUSION}

With the increase in the number of electric vehicles, the need for electric charging stations is increasing day by day. For a sustainable world, it is extremely important to meet this need from renewable energy sources such as solar energy. In this study, a suitable site selection analysis was carried out for electric charging stations operating with solar energy. In the analysis process, 13 suitable station locations were determined for the Ankara-IStanbul highway by using GIS and MCDM. It has been seen that the evaluation of many criteria in the analyzes made with MCDM supported GIS provides great convenience in choosing the appropriate location. Future study to improve the analysis are listed below.

- The study is very open to development and criteria change. In future studies, more detailed criteria will be selected and the results will be updated.

- Solar energy has been chosen as a renewable energy source within the scope of this study, but depending on the route to be determined, different renewable energy sources can be used for this study.

- The current study area has been determined as the AnkaraIstanbul highway. The proposed study is applicable by integrating it into other provincial roads with high solar energy potential.

- To use the designated charging station areas more efficiently and comprehensively, they can be transformed into areas where the driver and their families can perform social activities, and quality time can be spent during charging.

\section{ACKNOWLEDGEMENTS}

We would like to thank the General Directorate of Highways (Turkey) for sharing the traffic volume data with us.

\section{REFERENCES}

Ali, S.; Taweekun, J.; Techato, K.; Waewsak, J.; Gyawali, S., (2019)., GIS-based site suitability assessment for wind and solar farms in Songkhla, Thailand, Crossref DOI link: https://doi.org/10.1016/J.RENENE.2018.09.035

Ayday ,C.; Yaman, N.; Sabah, L. ; Höke, O., (2016)., Use of Open Source Coded GIS in Solar Power Plant Site Selection-Eskişehir Province Example, 6. Remote Sensing-GIS Symposium, Adana.

Bayram,ER I. Ş.; Bayhan, S.; Zafar, U., (2021)., A GIS-based Optimal Facility Location Framework for Fast Electric Vehicle Charging Stations, (16) (PDF) A GIS-based Optimal Facility Location Framework for Fast Electric Vehicle Charging Stations (researchgate.net)

Çanka Kılıç, F ., (2015)., Solar energy. Latest Situation and Production Technologies in Turkey Engineers and Machines, 56 (671) , 28-40 . Erişimi adresi: https://dergipark.org.tr/tr/pub/muhendismakina/issue/54341/73624 5

Ministry of Environment and Urbanization, (2018)., Ratio of Electricity Produced from Renewable Sources, Table 29. Distribution of Electricity Production from Renewable Sources in 2018. Access address: https://cevreselgostergeler.csb.gov.tr/yenilenebilir-kaynaklardanuretilen-elektrik-orani-i-85810

Chen, J., (2017)., California public electric vehicle charging stations' accessibility to amenities: A GIS network analysis approach, Master's Projects, and Capstones. 565

Communication from the Commission to the European Parliament (2019)., The European Council, The Council, The European 
Economic And Social Committee And The Committee Of The Regions The European Green Deal. COM/2019/640 Final

Deniz, M.; Topuz, M., (2018)., Determination of Alternative Dump Sites in Uşak Central District Using Multi-Criteria DecisionMaking Methods and Analytical Hierarchy Technique with the Support of Geographic Information Systems (GIS). Journal of History Culture and Art Research, 7(5), 544-578. doi:http://dx.doi.org/10.7596/taksad.v7i5.1830

World Energy Council Turkish National Committee, (2017)., Energy Efficiency Working Group, Low Carbon Emission Transportation Sector Strategies of the European Union and Turkish Automotive Sector

Gerçek, Y., (2018)., Determination of the Most Appropriate Location for Solar Power Plants with GIS: The Case of Malatya Province, (Master's Thesis)Karadeniz Technic University/ Graduate School of Natural and Applied Sciences,Trabzon

Gönül, Ö.; Duman, A. C.; Güler Ö., (2021)., Electric Vehicles and Charging İnfrastructure in Turkey: An overview, Renewable and Sustainable Energy Reviews, Volume 143, 110913, ISSN 1364. 0321, https://doi.org/10.1016/j.rser.2021.110913.

Ibrahim, G. R. F.; Hamid, A. A.; Darwesh, U. M.; Rasul, A., (2021)., A GIS-based Boolean logic-analytical hierarchy process for solar power plant (case study: Erbil Governorate-Iraq), Crossref DOI link: https://doi.org/10.1007/S10668-020-00862-3

Kausika, B. B.; van Sark, W. G. J. H. M., (2021)., Calibration and Validation of ArcGIS Solar Radiation Tool for Photovoltaic Potential Determination in the Netherlands, https://doi.org/10.3390/en14071865

Kaya, Ö.; Tortum, A.; Alemdar, K., (2020)., Çodur, M. YasinSite selection for EVCS in Istanbul by GIS and multi-criteria decisionmaking. Crossref DOI link: https://doi.org/10.1016/J.TRD.2020.102271.

Lindberg, O.; Birging, A.; Widén, J.; Lingfors, D., (2021)., PV park site selection for utility-scale solar guides combining GIS and power flow analysis: A case study on a Swedish municipality, Crossref

link: https://doi.org/10.1016/J.APENERGY.2020.116086

Prieto-Amparán, J.A.; Pinedo-Alvarez, A.; Morales-Nieto, C.R.; Valles-Aragón, M.C.; Álvarez-Holguín, A.; Villarreal-Guerrero, F. (2021)., A Regional GIS-Assisted Multi-Criteria Evaluation of SiteSuitability for the Development of Solar Farms. Land, 10, 217. https://doi.org/ 10.3390/land10020217

Sağlam, B.; Begçecanlı, B., (2021)., Development in the Electric Vehicle Market Will Accelerate With the Implementation of TOGG. Access address: https://www.aa.com.tr/tr/ekonomi/toggunhayata-gecmesiyle-elektrikli-arac-pazarindaki-gelisimhizlanacak/2132146

Sánchez-Lozano, J. M.; Teruel-Solano, J.; Soto-Elvira, P. L., \& García-Cascales, M. S., (2013)., Geographical Information Systems (GIS) and Multi-Criteria Decision Making (MCDM) methods for the evaluation of solar farms locations: Case study in south-eastern Spain. Renewable and sustainable energy reviews, 24, 544-556.

Soydan, O., (2021)., Solar power plants site selection for sustainable ecological development in Nigde, Turkey, $S N$ Applied Sciences | https://doi.org/10.1007/s42452-020-04112-z

Tercan, E.; Eymen, A.; Urfalı, T.; Saracoğlu, B. O., (2021)., A sustainable framework for spatial planning of photovoltaic solar farms using GIS and multi-criteria assessment approach in Central Anatolia, Turkey, https://doi.org/10.1016/j.landusepol.2020.105272

Uyan, M., (2013)., GIS-based solar farms site selection using analytic hierarchy process (AHP) in Karapinar region, Konya/Turkey, doi: http://dx.doi.org/10.1016/j.rser.2013.07.042

Yalçın, C.; Yüce, M., (2020)., Determination of Suitable Areas for Solar Power Plant (GES) Investment in Burdur by GIS Method. geomatics , 5 (1) , 36-46 . DOI: 10.29128/geomatik.561962 Retrieved from https://dergipark.org.tr/tr/pub/geomatik/issue/48883/561962

Y1lmaz, M., (2012)., Turkey's Energy Potential and Importance of Renewable Energy Sources in terms of Electricity Production. Ankara University Journal of Environmental Sciences, 4 (2), 33-54. DOI: 10.1501/Csaum_000000064

Zambrano-Asanza, S.; Quiros-Tortos, J.; Franco J., (2021)., Optimal site selection for photovoltaic power plants using a GISbased multi-criteria decision making and spatial overlay with electric load, https://doi.org/10.1016/j.rser.2021.110853

\section{Web Sources:}

URL1. haritasi/turkiye

https://www.enerjiatlasi.com/gunes-enerjisi-

URL2. https://land.copernicus.eu/user-corner/technicallibrary/corine-land-cover-nomenclature-guidelines/html

URL3. https://www.mgm.gov.tr/kurumici/radiasyon_iller.aspx 